\title{
Shrink-swell potential, hydraulic conductivity and geotechnical properties of clay materials for landfill liner construction**
}

\author{
Marcin K. Widomski ${ }^{*}$, Witold Stępniewski ${ }^{1}$, Rainer Horn², Andrzej Bieganowski ${ }^{3}$ Lucjan Gazda \\ Matgorzata Franus ${ }^{4}$, and Matgorzata Pawtowska ${ }^{1}$

\begin{abstract}
${ }^{1}$ Faculty of Environmental Engineering, Lublin University of Technology, Nadbystrzycka 40 B, 20-618, Lublin, Poland ${ }^{2}$ Institute for Plant Nutrition and Soil Science, Christian Albrechts University, Hermann-Rodewald-Straße 2, Kiel, Germany ${ }^{3}$ Institute of Agrophysics, Polish Academy of Sciences, Doświadczalna 4, 20-290 Lublin, Poland
\end{abstract} \\ ${ }^{4}$ Faculty of Civil Engineering and Architecture, Lublin University of Technology, Nadbystrzycka 40, 20-618 Lublin, Poland
}

Received March 2, 2015; accepted June 11, 2015

A b s t r a c t. This paper presents studies concerning the applicability of two clay materials for the construction of a sustainable landfill liner. The studies consisted in determination of basic characteristics of the materials, eg particle size distribution, bulk density, particle density, total porosity, pore size, mineralogy, specific surface area, nanoparticle size, and Atterberg limits, as well as measurements of their geotechnical and hydraulic parameters, such as in situ saturated hydraulic conductivity, modules of primary and secondary compression, cohesion, and angle of internal friction. Furthermore, the effects of compaction performed by the Proctor method at various water contents on swelling and shrinkage characteristics and saturated hydraulic conductivity were investigated in order to determine the compliance with the national requirements for selection of material for landfill liner construction. The determined characteristics and geotechnical parameters of the tested clay materials allowed qualifying them as suitable for municipal landfill construction. The shrinkage potential of the tested clays observed was rated as moderate to very high. The cyclic drying and rewetting of the clay materials performed resulted in a significant increase in saturated hydraulic conductivity. Thus, the clay sealing layers, as part of a multilayer liner, should be very carefully operated, preventing the drying out of the clay sealing and assuring the possibility of its constant saturation.

K e y w or d s: clay material, clay liner, compaction, hydraulic conductivity, swell-shrinkage potential

\section{INTRODUCTION}

Landfilling of municipal wastes over an extended period may pose a major threat to the environment, as it results in biological, chemical, and physical processes in the waste body. This is related to the long-lasting and mainly unpre-

*Corresponding author e-mail: M.Widomski@wis.pol.lublin.pl **This work was financed from the budget for science as research project No. 7550/B/T02/2011/40. dictable possible migration of various pollutants to soil, water, and air due to the unknown composition of the waste itself. Thus, the protection of the natural environment and limiting the threats caused by landfills should include minimization of leachate generation and infiltration, prevention of uncontrolled migration of landfill gas (containing greenhouse gases like methane and carbon dioxide) (Lou and Nair, 2009), as well as reduction of generation and migration of odours (Butt et al., 2008).

The main source of landfill leachate is surface water, which originates from precipitations and melting snow. Infiltration to and from the waste body should, in general, be completely prevented by the top and the bottom liners. Both liners are often constructed from natural materials with appropriate permeability and capillary barrier systems and are often additionally supported by plastic or geosynthetic membranes (Aldaeef and Rayhani, 2014; Bagchi, 2004; Laner et al., 2011, 2012; Simon and Müller, 2004). In the European Union, the required saturated hydraulic conductivity $\left(K_{s}\right)$ for mineral sealing liners is lower than $110^{-9} \mathrm{~m} \mathrm{~s}^{-1}$ (99/31/EC). Isolation of landfills should be long-term and self-sustainable (Laner et al., 2012; Horn and Stępniewski, 2004), especially the permanent one, but temporary solutions may also be included (Widomski et al., 2015).

Various types of clays are natural materials with a very low hydraulic conductivity commonly applied in construction of sealing liners of landfills (Bello, 2013; Daniel and $\mathrm{Wu}, 1993)$. Application of clays as construction materials for landfill liners should be verified in regard to its compliance with local legal standards (Journal of Laws, 2013

(C) 2015 Institute of Agrophysics, Polish Academy of Sciences 
item 523; Council Directive 99/31/EC), as well as the technical engineering guidelines, commonly focused on the particle size distribution, saturated hydraulic conductivity, linear shrinkage, and geotechnical characteristics such as Atterberg limits, angle of internal friction, cohesion etc. (Arch, 1998; Bagchi, 1990; Daniel and Koerner, 1995; Rowe et al., 1995; Wysokiński, 2007). The natural permeability of clay materials may be reduced by additional compaction. This is the case when natural materials in situ present values higher than the required ones or when extraction and transport of the clay material are necessary (Benson and Trast, 1995; Simon and Müller, 2004; Zhang et al., 2006).

The efficiency of compaction as a shear process depends on the applied compaction energy and conditions, including the moulding water content (Benson and Trast, 1995; Bello, 2013; Cuisinier et al., 2011; Horn et al., 2015; Osinubi and Nwaiwu, 2005; Whalley et al., 2012). The bulk density of clay changes with the increase in the water content during compaction. At first, it increases and begins to decrease having reached the maximum value known as Proctor density. Proctor density is commonly understood as the maximum possible compaction depending on the applied energy and water content (Baumgartl et al., 2004). However, the saturated hydraulic conductivity can decrease either with an increasing or decreasing bulk density, which can be affected by the moulding water content, as well as by the way of storage including the inevitable layering (Hamdi and Srasra, 2013; Zhang et al., 2006).

Nevertheless, the application of clay compacted at various water contents as a material for the sealing layer should include characterization of its swelling and shrinkage properties, resulting from geotechnical characteristics (Basma et al., 1996). Swelling and shrinkage properties of clays are commonly connected with possible cracking, which essentially increases their saturated hydraulic conductivity. Water is an important factor in stress changes in clays. The pressure of pore water affects - through rearrangement of particles in the clay layer - the resulting effective stress and the long-term internal rigidity, as well as the hydraulic and pneumatic impermeability of mineral liners. Water also changes friction forces among soil particles, affecting the stability of the system. In the case of unsaturated conditions, stress resulting from the water potential may be defined as tensile stress (Baumgartl et al., 2004), which increases along with the decreasing water potential. When the tensile stress is greater than the tensile strength of the clay material, cracks appear.

Additionally, drying and rewetting - cyclic, partial, or total - which is possible during the long-term performance of liners exposed to variable atmospheric conditions, may also change the capability of clay of vertical and volumetric deformations (Tripathy and Rao, 2009) and considerably affect its hydraulic properties (Baumgartl et al., 2004; Pires et al., 2005; Seguel and Horn, 2006). Each drying decreases the water potential by moving the particles to the positions of minimum inner energy in order to increase the stability of the system. Hence, additional cracking appears, and is further enhanced by repeated rewetting and redrying (Baumgartl et al., 2004). Thus, the long-term self-sustainability of the sealing layer may be questionable, as it is either exposed to atmospheric conditions or threatened by dehydration caused by a low water retention capacity of drainage or cultivation layers, as well as a significant slope inclination that results in considerable lateral flows.

The Polish national standards (Journal of Laws, 2013 item 523) require that the main component of a municipal landfill liner - the clay sealing layer - should have hydraulic conductivity lower than $110^{-9} \mathrm{~m} \mathrm{~s}^{-1}$ and thickness equal to $0.5 \mathrm{~m}$. It should also be supported by a synthetic geomembrane. On the other hand, the top recultivation layer with a thickness equal to $1.0 \mathrm{~m}$ should be separated by a $0.5 \mathrm{~m}$ thick sand drainage layer with saturated hydraulic conductivity higher than $110^{-4} \mathrm{~m} \mathrm{~s}^{-1}$. The difference in hydraulic conductivity of the two adjoining layers reaching five orders of magnitude causes a significant resistance of vertical infiltration flow and directs the velocity vector horizontally. The greater the inclination of the liner slope, the lower the possibility for water to infiltrate into the clay liner. The above-mentioned situation is not a problem in the case of saturated clay sealing, which is not prone to shrinking and cracking. However, in the case of clay sealing barriers compacted at low water contents or dried due to exposure to atmospheric conditions, limited infiltration may result in problems connected with rehydration of the barrier. The duration of water retention in the sandy drainage layer, which facilitates infiltration into the clay layer may be insufficient. This makes shrinkage, cracking, and the increase in the saturated hydraulic conductivity of the clay sealing possible.

Therefore, the questions concerning the applicability of selected clays as material for the sealing layer, as well as the future self-sustainability of such liners, are still unanswered. In our opinion, mere compliance with the national requirements concerning geotechnical properties, linear shrinkage, and saturated hydraulic conductivity may be insufficient to ensure long-term self-sustainability of a mineral liner understood as the capability of the liner to sustain its sealing properties in time related to various atmospheric conditions.

The aim of this paper was to characterize the hydrological and geotechnical properties of two clay materials compacted at different water contents, which affect the applicability and self-sustainability of a landfill liner.

\section{MATERIALS AND METHODS}

The studies consisted in measurements of saturated conductivity, swell-shrink characteristics, and geotechnical properties of two clay materials compacted with the Proctor method at various water contents ranging from 0.13 to $0.27 \mathrm{~kg} \mathrm{~kg}^{-1}$ for material sampled in Bychawa, Poland, 
and at water contents spanning from 0.14 to $0.25 \mathrm{~kg} \mathrm{~kg}^{-1}$ for material sampled in Lazek Ordynacki, Poland. The investigations included:

- determination of the basic characteristics of the two clay materials, including the physicochemical and geotechnical characterization of both,

- measurements of their saturated hydraulic conductivity in situ,

- laboratory measurements of saturated hydraulic conductivity of the materials compacted with the Proctor method at various water contents,

- assessment of the swelling and shrinkage potential of the materials following Proctor compaction at various water contents,

- measurements of saturated hydraulic conductivity of the materials following one, two, and three cycles of drying and wetting.

Miocene clays used in our studies were sampled in two locations, Bychawa (clay material B) and Lazek Ordynacki (clay material L), Lublin Voivodeship, SE part of Poland. Neither of the clays were previously used or considered to be used as a material for hydroisolation.

The tested materials were sampled from existing open cast mining pits at a depth of approx. 0.6-1.0 m. They were subjected to macroscopic description in situ. The in situ saturated hydraulic conductivity of the tested materials was measured by the GeoN falling head field permeameter for fine-grained soils, made by Geo Nordic, Stockholm, Sweden.

The particle size distribution of the tested materials was determined with the standard sedimentation method according to PN-B-04481:1988. The particle size distribution following the saturated hydraulic conductivity tests was measured with the laser diffraction method by means of a Mastersizer 2000 laser diffractometer, manufactured by Malvern, UK. The application of the two different methods for measurement of particle size distributions was dictated by the fact that the results obtained differed significantly from one another (Bieganowski et al., 2013; Ryżak and Bieganowski, 2010). Therefore, the sedimentation method was used to determine the particle size distribution of the investigated materials, whereas the laser diffraction method allowed showing subtle differences in the particle size distribution (which was impossible in the sedimentation method).

Solid particle density was measured in a le Chatelier flask and gas pycnometer according to Langer, Eijkelkamp, The Netherlands, while the gravimetric water content was obtained with the standard weight method according to ASTM C566 - 13 (2007).

Specific surface area of the particles and micropore area were measured with the nitrogen adsorption method, using an ASAP 2020 Physisorption Analyzer by Micrometrics, USA. Cation exchange capacity (CEC) values were determined with the use of $\mathrm{BaCl}_{2}$ and atomic absorption spec- trometry (ASA), as described by Derkowski et al. (2006). The microscopic analyses of structure of the tested clays were performed with a Quanta SEM 200 FEG scanning electron microscope by FEI, USA. Qualitative mineralogical composition of the tested materials was determined with the X-ray diffraction (XRD) method using Panalytical X'Pert APD with a PW 3020 goniometer and a $\mathrm{Cu}$ lamp with a graphite monochromator, Netherlands. Semi-quantitative composition of the raw sample and of the clay fraction was determined with the differential thermal analysis (DTA) method using TG-DTA/DSC Setsys 16/18 thermobalance, produced by Setaram, France.

Geotechnical properties, such as the plastic limit and the liquid limit of the studied clay materials, were determined through standard procedures (PKN-CEN ISO/ TS 17892-12, 2009). Measurements of modulus of primary and secondary compressibility were performed in a 26-W70302 oedometer by Wykeham Farrance, ITL, India, according to the PKN-CEN ISO/TS 17892-5 (2009) standard. The internal friction angle and cohesion were measured in DIGISHEAR shearing test apparatus by Wykeham Farrance, India, according to PKN-CEN ISO/ TS 19892-10 (2009). Measurements were conducted in 60x60x60 mm boxes under consolidated drained test conditions (CD), in undisturbed samples with natural water content, after preliminary sample consolidation, without water outflow during the test (consolidated undrained test, $\mathrm{CU})$. The consolidating load was the same for all the tested samples. The maximum value of shear stress $\tau_{\max }$ was assumed as the shear strength of the material $\tau_{f}$. The velocity of horizontal movement amounted to $0.05 \mathrm{~mm} \mathrm{~min}^{-1}$.

The main laboratory measurements of saturated hydraulic conductivity of the studied clay materials compacted with the standard Proctor method at various water contents were performed in $\mathrm{H}-4145$ falling head permeameters for compacted soils by Humboldt Mfg. Co, USA, according to ASTM D5856 (2013). The materials were compacted at the following water contents (by weight): $0.13,0.15$, $0.16,0.17,0.20,0.22,0.23,0.25,0.26$, and $0.27 \mathrm{~kg} \mathrm{~kg}^{-1}$ for Bychawa clay and 0.14, 0.16, 0.17, 0.19, 0.20, 0.21, 0.22, 0.23 , and $0.25 \mathrm{~kg} \mathrm{~kg}^{-1}$ for Lazek Ordynacki material, two moulds for each water content.

After the laboratory measurements of saturated hydraulic conductivity, the swelling and shrinkage characteristics were determined in order to assess the swelling and shrinking potential of the tested clays. Swelling characteristics were measured for saturated samples following the saturated hydraulic conductivity tests, directly in the applied moulds of the permeameter for compacted soils. The height of the sample for calculation of the swelling was measured using a vernier caliper at 10 regularly distributed locations for each sample. Shrinkage was measured in $100 \mathrm{~cm}^{3}$ cylindrical samples taken from the compaction moulds, according to the methodology similar to that of Gerbhardt et al. (2012). Shrinkage of the cylindrical samples was 
measured by a vernier caliper with an accuracy of $0.05 \mathrm{~mm}$ in 8 selected locations (as repetitions), both for the diameter and the height. Afterwards, the measured dimensions were used to calculate two dimensionless shrinkage indicators, $r_{s}$ and COLE (Bronswijk, 1990; Grossman et al., 1968), according to the following formulas:

$$
r_{s}=\frac{\ln \frac{V_{d}}{V_{s}}}{\ln \frac{Z_{d}}{S_{s}}},
$$

where: $r_{s}$-dimensionless geometry factor, $V_{d}, Z_{d}-$ dry volume $\left(\mathrm{m}^{3}\right)$ and height $(\mathrm{m}), V_{s}, Z_{s}$ - saturated volume $\left(\mathrm{m}^{3}\right)$ and height $(\mathrm{m})$;

$$
\text { COLE }=\left(\frac{V_{s}}{V_{d}}\right)^{\frac{1}{3}}-1,
$$

where: COLE - dimensionless coefficient of linear extensibility.

The dimensionless geometry factor $r_{s}$ for vertical deformation should be equal to 1.0. Values between 1.0 and 3.0 are typical for the predominant vertical deformation, $r_{s}=3.0$ is found for isotropic deformation, whereas values of $r$ greater than 3.0 are typical if the horizontal deformation is predominant. Values of the coefficient of linear extensibility (COLE) lower than 0.03 indicate low shrinkage potential. Values in the range of 0.03-0.06 are related to moderate shrinkage potential. Values from 0.06 to 0.09 are typical for high potential and values greater than 0.09 indicate very high shrinkage potential (Gebhardt et al., 2012).

Shrinkage and swelling potentials for all the applied values of moulding water contents were calculated as the differences between dry bulk density after compaction and dry bulk density following swelling and shrinkage (eg Bauer et al., 2001; Horn and Stępniewski, 2004).

Additionally, in order to assess the sustainability of clay materials which are likely to be used for liner construction, the compacted and saturated materials were sampled in standard $100 \mathrm{~cm}^{3}$ steel cylinders; one cylinder was sampled from one mould. All the samples were air dried at room temperature - approx. $20^{\circ} \mathrm{C}$ - and rewetted through capillary saturation. After each of the three cycles of drying and wetting, additional saturated hydraulic conductivity measurements were performed with constant and falling head methods (depending on the value of the measured parameter) in a laboratory permeameter made by the former IMUZ (Institute for Land Reclamation and Grassland Farming), Lublin, Poland.

\section{RESULTS AND DISCUSSION}

The Bychawa clay presented in Fig. 1 is a rusty-yellow kaolinite-illite-smectite material with a very fine particle and colloidal structure visible in the SEM (scanning electron microscope) picture. The Lazek Ordynacki clay
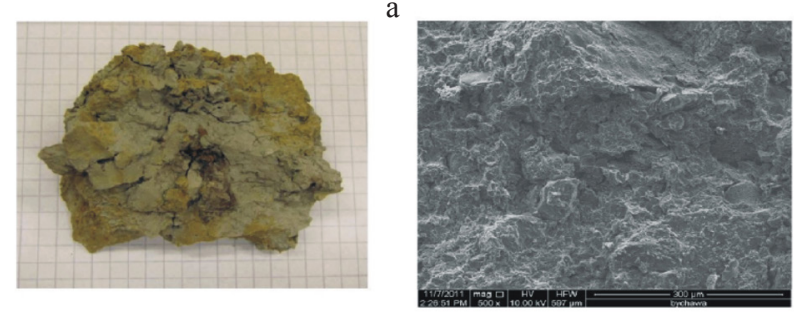

Macro photo

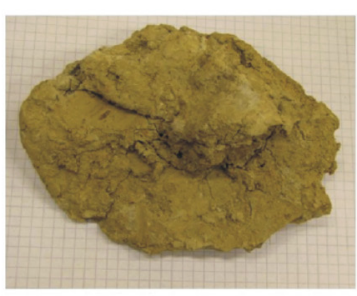

b

SEM 500x magnification

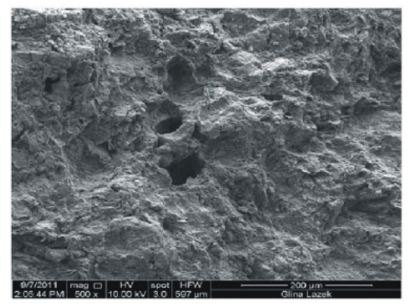

Fig. 1. Macro photos and SEM pictures of clay materials from: $\mathrm{a}$ - Bychawa and b- Lazek Ordynacki.

T a b l e 1. Semi-quantitative results of mineralogical investigations of the original materials $(\mathrm{K}$ - kaolinite, $\mathrm{I}$ - illites and $\mathrm{S}$ - smectites). $\mathrm{K} /(\mathrm{I}+\mathrm{S})$ - ratio of kaolinite to the sum of illites and smectites)

\begin{tabular}{lcc}
\multirow{2}{*}{$\begin{array}{l}\text { Treatment } \\
\text { (\%) }\end{array}$} & \multicolumn{2}{c}{ Location } \\
\cline { 2 - 3 } Clay minerals & Bychawa & Lazek Ordynacki \\
$\mathrm{K} /(\mathrm{I}+\mathrm{S})$ & 90 & 60 \\
$\mathrm{FeOOH}$ & 11 & 11 \\
$\mathrm{CaCO}_{3}$ & 8 & 5 \\
Quartz and feldspars & 2 & 10 \\
\hline
\end{tabular}

(Fig. 1) is a rusty-olive kaolinite-smectite-illite clay with coarse crystalline clay particles. The mineralogical composition of the studied materials determined with the XRD method comprises quartz, calcite, feldspars, illite, smectite, and kaolinite for the Bychawa clay and quartz, calcite, feldspars, illite, smectite, kaolinite, and chlorite for the Lazek Ordynacki clay.

On the basis of the DTA of the original clay material and the isolated clay fraction, a semi-quantitative content of the clay minerals, iron oxy-hydroxides, and calcium carbonate (Table 1) was determined. The analysed materials do not contain any substantial (measurable by thermal analysis) amounts of organic matter.

Both materials considered are characterized by a similar set of clay minerals. A measure of the set of clay minerals is the ratio of kaolinite (K) to swelling illites (I), smectites (S), and mixed structures of illites-smectites (I-S). The 
T a b l e 2. Detailed characteristics of the examined clay materials

\begin{tabular}{|c|c|c|c|}
\hline \multirow{5}{*}{ Particle size fraction content $(\%)$} & & \multicolumn{2}{|c|}{ Sampling location } \\
\hline & & Bychawa (B) & Lazek Ordynacki (L) \\
\hline & Sand $2-0.05 \mathrm{~mm}$ & 12.0 & 4.5 \\
\hline & Silt $0.05-0.002 \mathrm{~mm}$ & 46.0 & 51.0 \\
\hline & Clay $<0.002 \mathrm{~mm}$ & 42.0 & 44.5 \\
\hline Parameter & Unit & & \\
\hline Particle density & & 2.72 & 2.68 \\
\hline Dry bulk density in situ & $\left(\mathrm{Mg} \mathrm{m}^{-3}\right)$ & 1.64 & 1.70 \\
\hline Wet bulk density in situ & & 2.07 & 2.06 \\
\hline Gravimetric water content in situ & $\left(\mathrm{kg} \mathrm{kg}^{-1}\right)$ & 0.26 & 0.21 \\
\hline Total porosity in situ & $\left(\mathrm{m}^{3} \mathrm{~m}^{-3}\right)$ & 0.397 & 0.366 \\
\hline Saturated hydraulic conductivity in situ & $\left(\mathrm{m} \mathrm{s}^{-1}\right)$ & $2.7510^{-10}$ & $1.3710^{-10}$ \\
\hline Plastic limit & & 24.6 & 24.5 \\
\hline Liquid limit & $(\%)$ & 52.1 & 58.8 \\
\hline Plasticity index & & 27.5 & 34.2 \\
\hline Modulus of primary compressibility & $(\mathrm{MPa})$ & 4.8 & 5.3 \\
\hline Modulus of secondary compressibility & (IVIr a) & 9 & 12.5 \\
\hline Internal friction angle & $\left({ }^{\circ}\right)$ & 8 & 8 \\
\hline Cohesion & $(\mathrm{kPa})$ & 61 & 41 \\
\hline Cation-exchange capacity CEC & $\left(\right.$ meq $\left.100 \mathrm{~g}^{-1}\right)$ & 36.1 & 31.8 \\
\hline Single point surface area at $\mathrm{P} / \mathrm{Po}=0.261$ & $\left(\mathrm{~m}^{2} \mathrm{~g}^{-1}\right)$ & 47.1 & 33.6 \\
\hline BET (Brunauer-Emmett-Teller) Surface area & & 48.1 & 34.3 \\
\hline t-Plot Micropore area & & 9.46 & 6.15 \\
\hline t-Plot External Surface area & & 38.6 & 28.2 \\
\hline $\begin{array}{l}\text { BJH (Barrett-Joyner-Halenda) adsorption } \\
\text { cumulative surface area of pores between } 1.70 \text { and } \\
300 \mathrm{~nm} \text { diameter }\end{array}$ & $\left(m^{2} g^{-1}\right)$ & 35.0 & 25.5 \\
\hline $\begin{array}{l}\text { BJH (Barrett-Joyner-Halenda) desorption } \\
\text { cumulative surface area of pores between } 1.70 \text { and } \\
300 \mathrm{~nm} \text { diameter }\end{array}$ & & 41.0 & 30.0 \\
\hline
\end{tabular}

contribution of the sum of clay minerals is substantially higher in the Bychawa clay. The Bychawa clay contains only a small amount of carbonate and a high amount $(8 \%)$ of iron forms. The Lazek Ordynacki clay is characterized by $10 \% \mathrm{CaCO}_{3}$ content.

The detailed characteristics of the tested materials, including, inter alia, particle size fraction content, dry and wet bulk density, particle density, total porosity, pore area, mine- ralogy, specific surface area, and nanoparticle size, Atterberg limits, as well as their geotechnical and hydraulic parameters like in situ saturated hydraulic conductivity, modules of primary and secondary compression, cohesion along with angle of internal friction, are presented in Table 2.

Despite the slightly different particle size distribution with the higher content of sand (12.0\% vs. $4.5 \%)$ and lower silt and clay fractions $(46.0 \% v s .51 .0 \%$ and $42.0 \% v s$. 
$44.5 \%$, respectively) in the Bychawa substrate, both tested materials were qualified as silty clays. Solid phase particle density, dry and wet bulk densities, as well as total porosity were similar (Table 2). Differences in the particle composition are reflected in the single point specific surface area, external surface area, and in situ saturated hydraulic conductivity, all of which were higher for the material sampled in Bychawa. Both substrates had nearly the same plastic limit, but the higher liquid limit of Lazek Ordynacki resulted in a higher plasticity index.

The laser diffraction measurements of changes in particle size distribution applied according to long lasting hydraulic conductivity tests showed no significant differences in clay fraction content. Thus, we may conclude that the continuous saturated hydraulic conductivity tests, lasting several weeks each, did not significantly affect the particle composition of the analyzed B and L clay materials.

The modulus of compressibility of both tested materials is greater than $5 \mathrm{MPa}$ and fulfils the national Polish criteria ( $5 \mathrm{MPa}$ ) of deformation for landfill liner construction (Wysokiński, 2007). The lower value of the compressibility modulus for the Bychawa clay under natural conditions indicates its lower consolidation. The national Polish strength criteria (Wysokiński, 2007) characterized by the minimal angle of internal friction of $3^{\circ}$ and minimal cohe- sion of $35 \mathrm{kPa}$ are met by both tested substrates. The angle of internal friction is equal for both tested materials $\left(8^{\circ}\right)$ but the values of cohesion are different (61 $\mathrm{kPa}$ for Bychawa vs. $41 \mathrm{kPa}$ for Lazek Ordynacki). The Bychawa material presents greater cohesion due to a significantly higher content of clay minerals (Table 1), which amounted to $90 \%$, in contrast to $60 \%$ for the Lazek Ordynacki material. The values of plastic and liquid limits obtained indicate technical applicability of the tested substrates for forming hydro-isolation barriers (Wysokiński, 2007).

The effect of compaction performed with the Proctor method at different water contents on the resulting bulk density and saturated hydraulic conductivity, as well as on bulk density after subsequent swelling and shrinkage is presented in Fig. 2. The results of saturated hydraulic conductivity $\left(K_{s}\right)$ measurements for both materials show a substantial decrease in the saturated hydraulic conductivity, with the increasing moulding water content. For the Bychawa material, the increase in the moulding water content from 0.13 to $0.27 \mathrm{~kg} \mathrm{~kg}^{-1}$ resulted in a decrease in saturated hydraulic conductivity from $1.0310^{-8}$ to approx. $7.5010^{-11} \mathrm{~m} \mathrm{~s}^{-1}$. A similar phenomenon was observed for the clay material sampled in Lazek Ordynacki. The increase in the moulding water content from 0.14 to $0.25 \mathrm{~kg} \mathrm{~kg}^{-1}$ caused a decrease in the measured coefficient of saturated

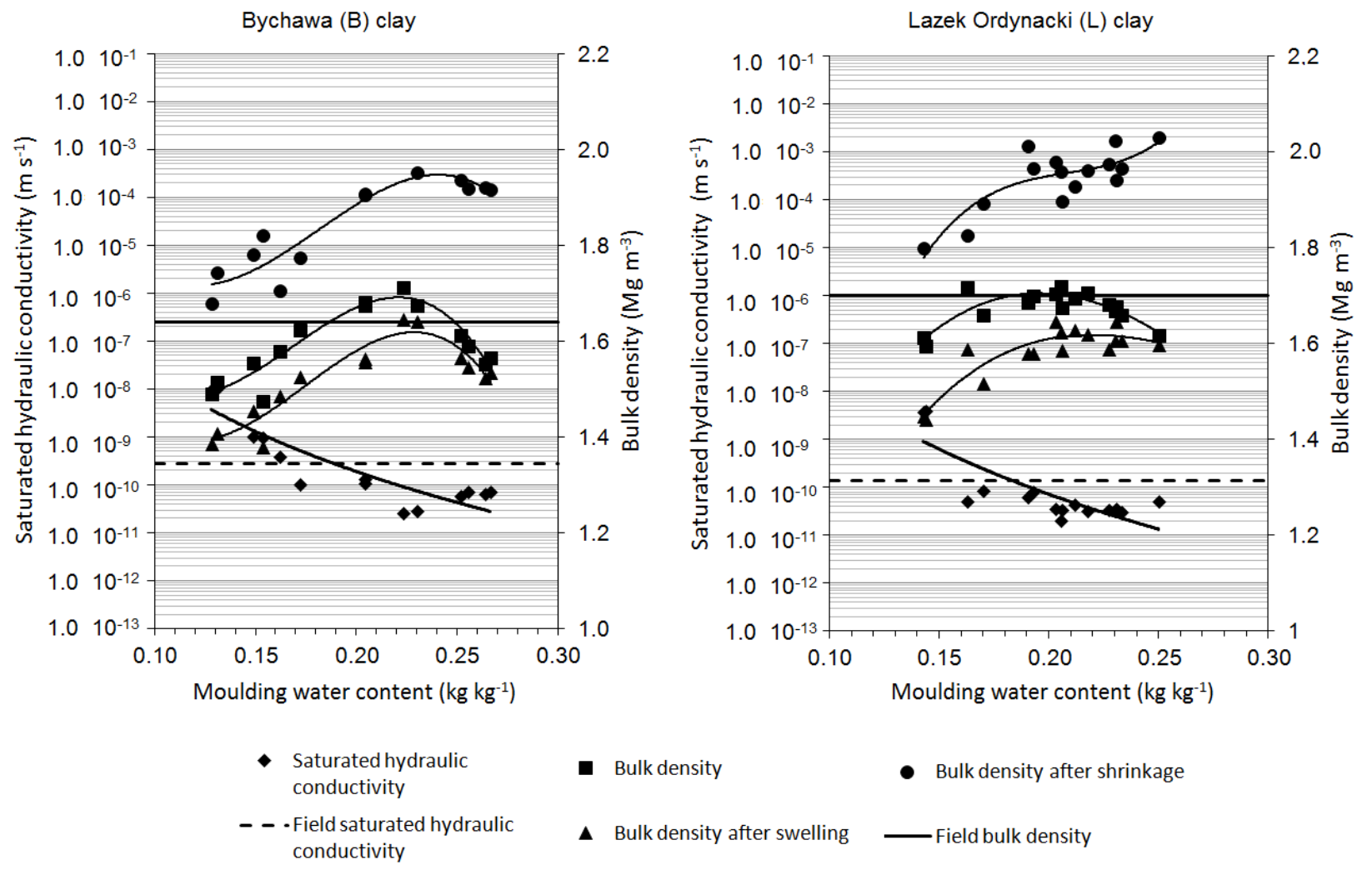

Fig. 2. The effect of the moulding water content during the Proctor test on the resulting dry bulk density and saturated hydraulic conductivity as well as on the dry bulk density after subsequent swelling and shrinkage. 
hydraulic conductivity from $3.8110^{-9}$ to approx. $5.2010^{-11}$ $\mathrm{m} \mathrm{s}^{-1}$. In both substrates, the lowest measured values of $K_{\mathrm{s}}$ were observed for moulding water contents lower than the maximum applied. The lowest value of $K_{s}$ for the Bychawa clay was equal to $2.7510^{-11} \mathrm{~m} \mathrm{~s}^{-1}$ for the moulding water content of $0.22 \mathrm{~kg} \mathrm{~kg}^{-1}$, while the lowest $K_{s}$ obtained for the Lazek Ordynacki material was $2.1010^{-11} \mathrm{~m} \mathrm{~s}^{-1}$ for the moulding water content of $0.21 \mathrm{~kg} \mathrm{~kg}^{-1}$.

However, both tested materials are similar in several ways. The lowest moulding water contents applied resulted in hydraulic conductivity higher than $1.0010^{-9} \mathrm{~m} \mathrm{~s}^{-1}$, which is allowed by the European standards (eg 1999/31/EC). Compaction at water contents above $0.20 \mathrm{~kg} \mathrm{~kg}^{-1}$ for the Bychawa material and $0.16 \mathrm{~kg} \mathrm{~kg}^{-1}$ for the samples from Lazek Ordynacki allowed lowering the value of saturated hydraulic conductivity to the range of $10^{-11} \mathrm{~m} \mathrm{~s}^{-1}$. Similarly, beside the lowest moulding water contents applied, the performed compaction allowed reduction of $K_{s}$ below the level observed under natural conditions.

The observed relation between dry bulk density of the compacted clays and their coefficient of saturated hydraulic conductivity is presented in Fig. 3. The increase in bulk density caused by the applied compaction reduced the value of the saturated hydraulic conductivity. The decrease in $K_{s}$ in relation to dry bulk density was greater for the Lazek Ordynacki clay material.

A typical relation between the applied moulding water content and the dry bulk density was observed in both tested materials. The maximum dry Proctor bulk densities for both analysed clay materials equal to 1.71 and $1.72 \mathrm{Mg} \mathrm{m}^{-3}$ were observed for the moulding water contents of 0.22 and $0.21 \mathrm{~kg} \mathrm{~kg}^{-1}$ for the Bychawa and Lazek Ordynacki clays, respectively. The minimal observed dry bulk density was achieved for the lowest values of the moulding water con-

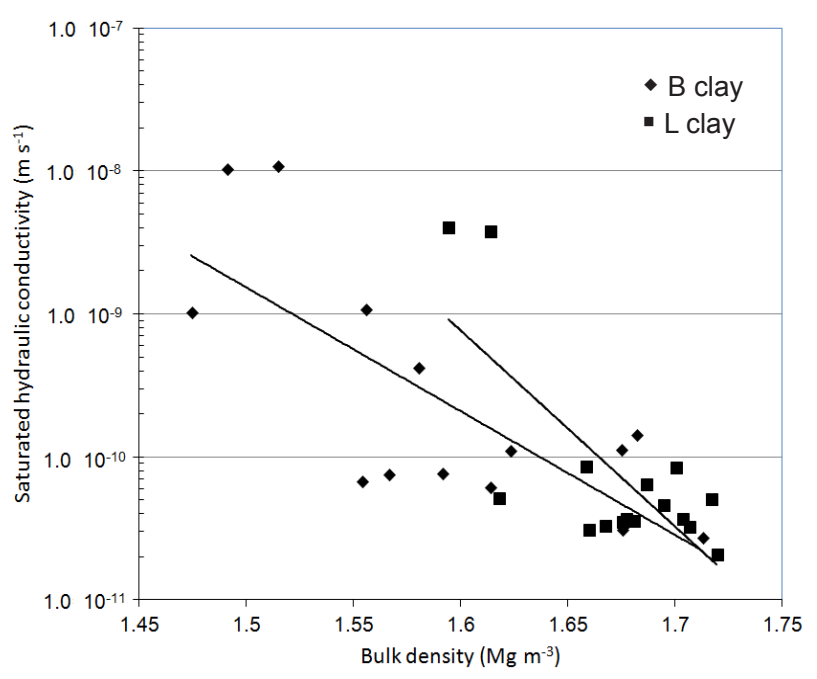

Fig. 3. Saturated hydraulic conductivity $v s$. dry bulk density of the tested materials (B - Bychawa, L - Lazek Ordynacki clays). tent, ie $1.50 \mathrm{Mg} \mathrm{m}^{-3}$ for $0.13 \mathrm{~kg} \mathrm{~kg}^{-1}$ and $1.59 \mathrm{Mg} \mathrm{m}^{-3}$ for $0.14 \mathrm{~kg} \mathrm{~kg}^{-1}$ for the Bychawa and Lazek Ordynacki samples, respectively.

Figure 2 also presents dry bulk densities for the tested clays following swelling and shrinkage. Both materials showed a significant decrease in bulk density after swelling and an increase in bulk density after shrinkage. Swelling of the Bychawa material resulted in dry bulk densities in the range of $1.38-1.65 \mathrm{Mg} \mathrm{m}^{-3}$, while in the case of Lazek Ordynacki, the dry bulk density ranged between 1.44-1.65 $\mathrm{Mg} \mathrm{m}^{-3}$. The difference between the initial dry bulk density (ie after compaction test) and the bulk density of soil after swelling, also known as swelling potential (eg Horn and Stepniewski, 2004), in both cases decreased with the increase in the moulding water content.

Both tested clay materials showed a significant increase in bulk density after shrinkage. The observed bulk density after shrinkage was in the range of 1.68-1.95 and 1.80$2.03 \mathrm{Mg} \mathrm{m}^{-3}$ for Bychawa and Lazek Ordynacki materials, respectively. There was a significant difference between the curves representing bulk density after shrinkage for the two tested materials. For the clay sampled in Lazek Ordynacki, no clear decrease was observed when the maximum bulk density value was reached after the shrinkage. Bulk density of the shrunk soil increased constantly along with the increase in the moulding water content, thus increasing the shrinkage potential.

In order to better illustrate the observed swelling and shrinkage capabilities of the tested materials, the relations of the shrinkage and swelling potential to the applied moulding water contents are presented in Fig. 4. The determined shrinkage potential was in the range of $0.13-0.37 \mathrm{Mg} \mathrm{m}^{-3}$ for the Bychawa material and $0.11-0.41 \mathrm{Mg} \mathrm{m}^{-3}$ for the samples from Lazek Ordynacki, while the swelling potential was in the range 0.03-0.12 and 0.02-0.16 $\mathrm{Mg} \mathrm{m}^{-3}$ for the Bychawa and Lazek Ordynacki materials, respectively. In both tested materials, a clear increase in the shrinkage potential and a decrease in the swelling potential due to the increase in the moulding water content were visible. Generally, the higher the moulding water content, the lower the swelling potential and the higher the shrinkage potential. Additionally, the rate of the change in both tested potentials, ie increase and decrease, was higher in the case of clay material sampled in Lazek Ordynacki. Thus, the higher sand content in the clay material sampled in Bychawa reduces its shrinkage and swelling potentials. The results presented in Figs 2 and 4 clearly show that the shrinkage potential of the two tested clay materials, which results in the possibility of soil cracking, is distinctly higher at the right, wetter side of the Proctor curve. Thus, sustainability of the clay barrier constructed from these materials may be limited by cracking and the increased hydraulic conductivity, resulting in significant infiltration and seepage (due to preferential flow) when high moulding water contents are applied. The calculated dimensionless coefficient of linear 
Bychawa (B) soil

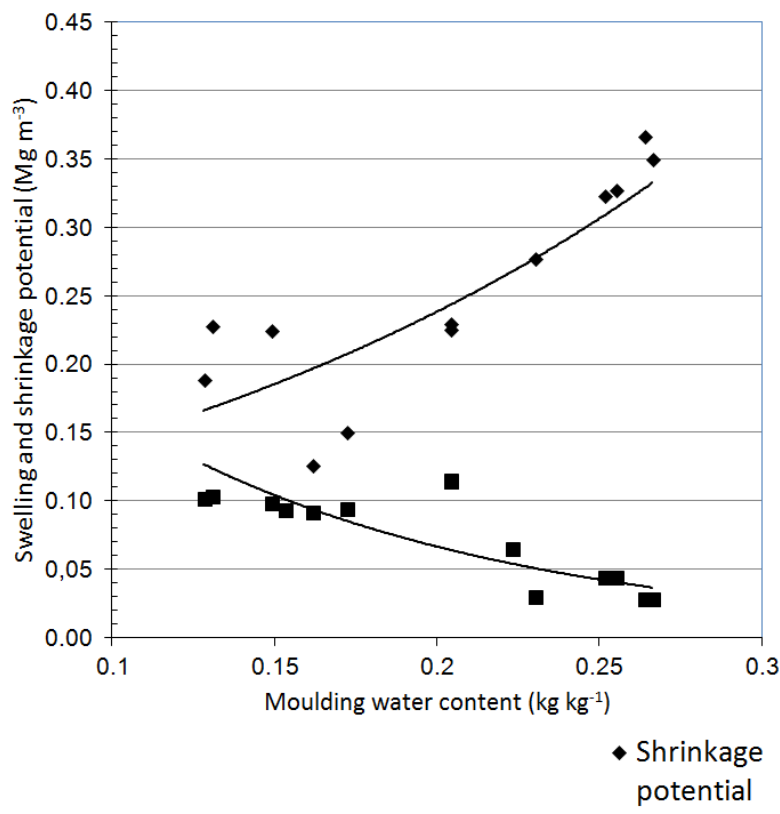

Lazek Ordynacki (L) soil

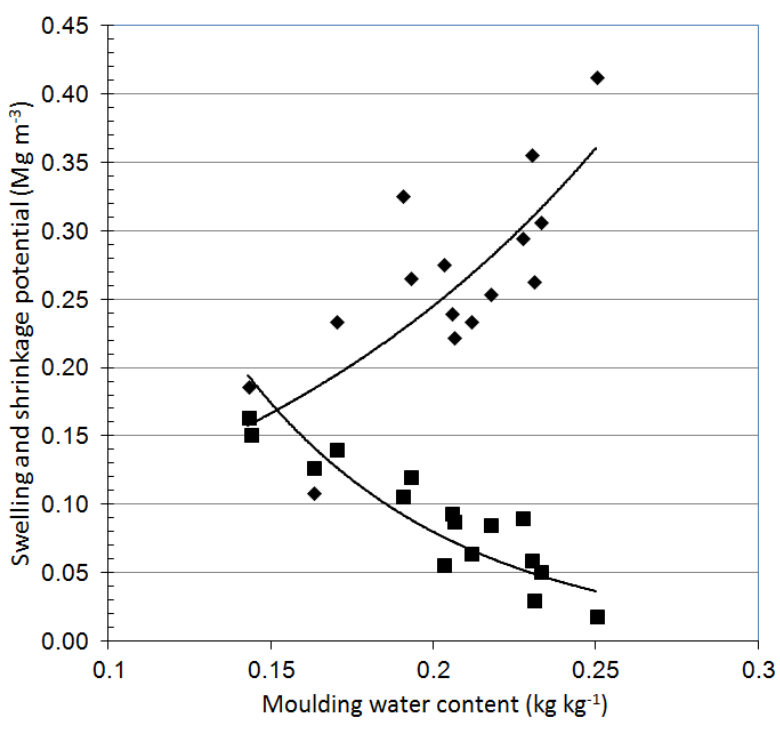

- Swelling

potential

Fig. 4. Shrinkage and swelling potential for the Bychawa and Lazek Ordynacki materials.

extensibility COLE for the tested clay materials was in the range 0.038-0.082 and 0.054-0.093 for Bychawa and Lazek Ordynacki, respectively. Therefore, the observed shrinkage of compacted samples allowed qualifying the shrinkage potential of the studied substrates as moderate to very high, according to COLE values. The analysis of the dimensionless geometry factor for soil shrinkage $r_{s}$ presented in Fig. 5 showed that the isotropic deformation was observed only in two cases. In other cases studied, vertical or horizontal deformation was dominant. The general observation is that despite the scattered data points, $r_{s}$ greater than 3.0 is dominant, which stands for larger horizontal deformation during the shrinkage. However, the tendency directing $r_{s}$ value to the area of preponderant vertical deformation with the increase in the moulding water content is visible.

Taking into account the observed significant shrinkage potential of both tested materials, additional measurements concerning sustainability of the sealing layer made of compacted clay materials were performed. The results of the measurements regarding saturated hydraulic conductivity after three cycles of drying and wetting for all the applied moulding water contents are presented in Fig. 6. To provide a better understanding of the problem of changes in saturated hydraulic conductivity of the compacted clays, the measured data for the tested materials before the first cycle of drying and wetting are also presented in Fig. 6 . The analysis of the results presented in Fig. 6 shows that drying and rewetting of the clay samples resulted in a significant increase in saturated hydraulic conductivity. The observed increase in $K_{s}$ reached the level of several orders

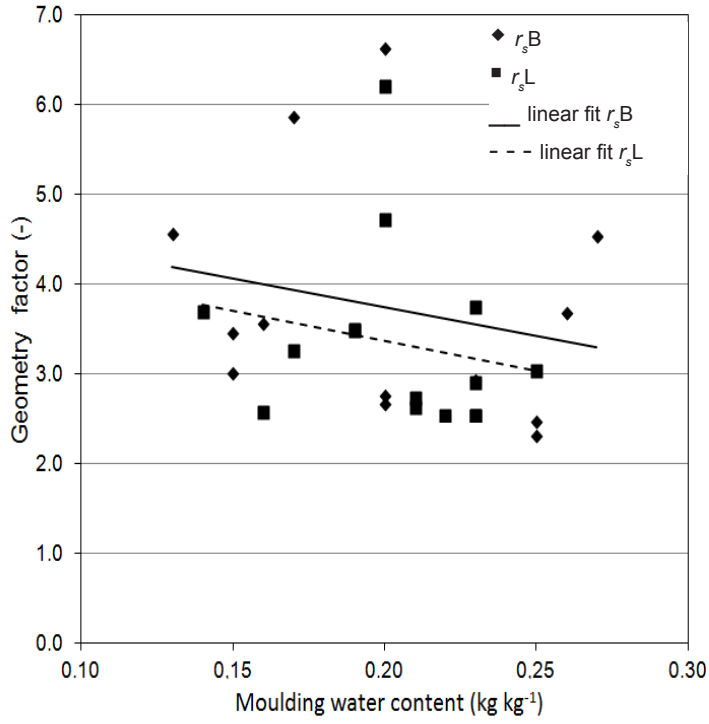

Fig. 5. Dimensionless shrinkage geometry factor for the tested clay materials $\left(r_{s} \mathrm{~B}, r_{s} \mathrm{~L}-\right.$ shrinkage geometry factor for the Bychawa and Lazek Ordynacki materials, respectively).

of magnitude; however, in some extreme cases, the saturated hydraulic conductivity of clays for both tested soils reached the values even greater than $1.0010^{-4} \mathrm{~m} \mathrm{~s}^{-1}$ after the third cycle. Such values are representative for sands. The above-mentioned phenomenon shows that the sustainability of a clay sealing liner may be secured only in the case of constant and permanent saturation. Under no circumstances can the clay liner be allowed to dry out, because 

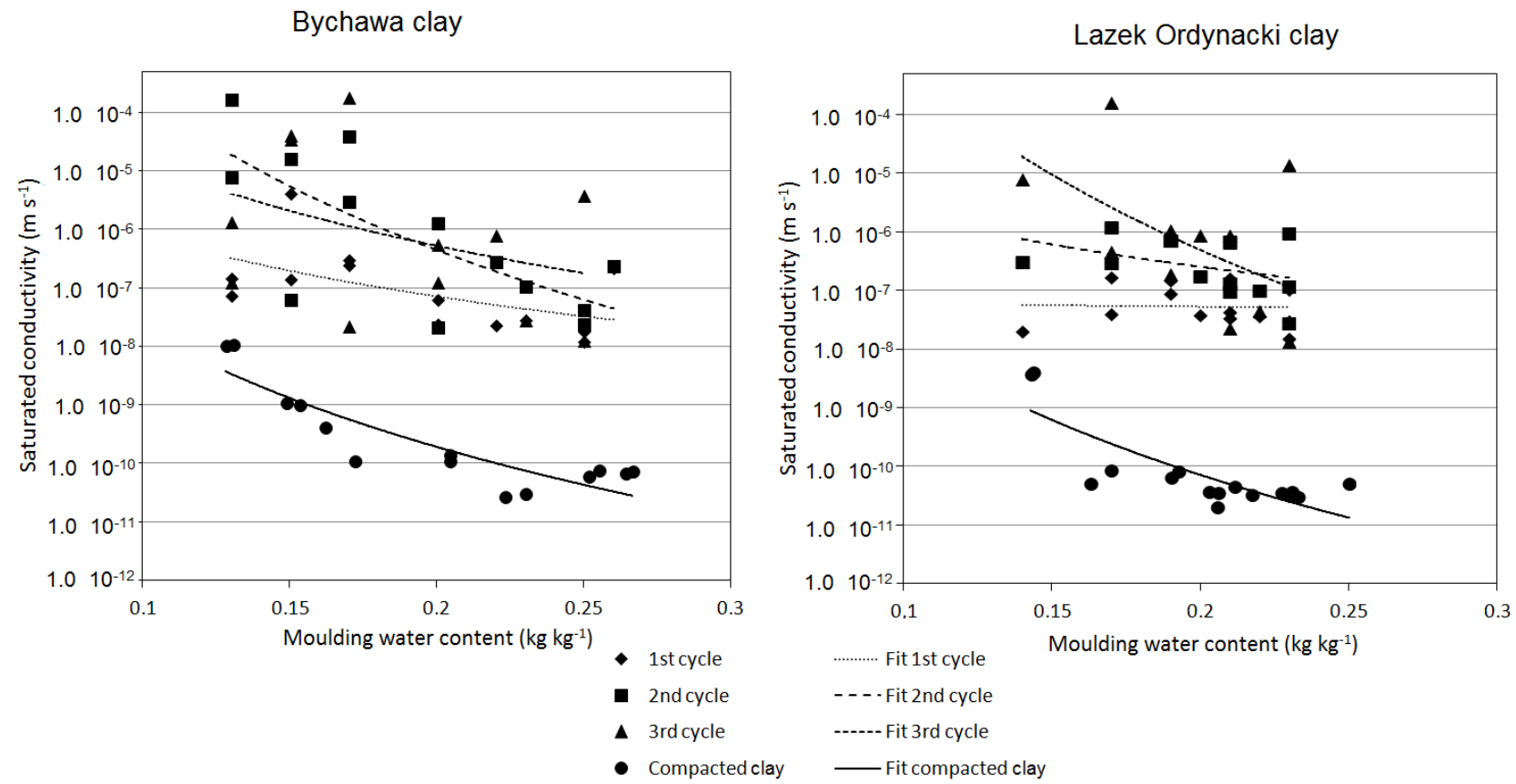

Fig. 6. Saturated hydraulic conductivity of the compacted materials after three cycles of drying and rewetting.

its subsequent saturation, or increase in the water content through any way of rewetting, will not restore its sealing properties.

Both tested materials present physical, hydraulic, and geotechnical characteristics meeting the popular criteria of acceptance for the construction of mineral landfill liners. The values of hydraulic conductivity measured in situ, equal to $2.7510^{-10} \mathrm{~m} \mathrm{~s}^{-1}$ for Bychawa and $1.3710^{-10} \mathrm{~m} \mathrm{~s}^{-1}$ for Lazek Ordynacki substrates, are lower than $1.010^{-9} \mathrm{~m} \mathrm{~s}^{-1}$, ie the value required by the Polish and European Union standards (Journal of Laws, 2013 item 523; Council Directive 99/31/EC) and specified in several handbooks and technical guidelines (Arch, 1998; Bagchi, 1990; Daniel and Koerner, 1995; Rowe et al., 1995). The application of the standard Proctor compaction allowed reaching the range of $\mathrm{K}_{\mathrm{s}} 10^{-10}-10^{-11} \mathrm{~m} \mathrm{~s}^{-1}$ in most cases. The required value of saturated hydraulic conductivity was not achieved only at the lowest moulding water contents applied in the range of $0.13-0.15 \mathrm{~kg} \mathrm{~kg}^{-1}$.

The particle size distribution of the tested materials presented in Table 2 shows a clearly higher content of clay $(<0.002 \mathrm{~mm})$ and silt $(0.05-0.002 \mathrm{~mm})$ fractions $-i e 88 \%$ for Bychawa and $96 \%$ for Lazek Ordynacki - than that $\geq 50 \%$ required by Bagchi (1990), $\geq 30-50 \%$ described by Daniel and Koerner (1995), and > 30\% suggested by Arch (1980). The content of the clay fraction, equal to 42 and $45 \%$ for the Bychawa and Lazek Ordynacki substrates, respectively, is also higher than the values suggested, ie $\geq 15 \%$ (Bagchi, 1990 ), $\geq 10-20 \%$ (Daniel and Koerner, 1995), and $>10 \%$
(Arch, 1998). The observed Atterberg limits also meet the popular requirements. The liquid limit (LL) equal to $52.1 \%$ for Bychawa and 58.8\% for Lazek Ordynacki is in line with the requirements presented by Bagchi (1990) LL $\geq 30 \%$ and Arch (1998) LL $<90 \%$. The plasticity index values of the tested substrates equal to 27.5 and $34.2 \%$ are higher than the required ones $\geq 7 \%$ (Daniel and Koerner, 1995; Rowe et al., 1995) and 10 or 15\% (Arch, 1998; Bagchi, 1990). Thus, according to the above-mentioned criteria, the tested substrates are suitable for mineral liner constructions.

On the other hand, there is a clear relationship between the applied moulding water content and shrinkage potential, which increased on the 'wet' side of the Proctor curve. The shrinkage potential increased significantly for moulding water contents higher than that of the maximum Proctor density. Moreover, the calculated dimensionless coefficient of linear extensibility (COLE) for both considered materials showed values that determine the shrinkage potential as moderate to very high. The analysed dimensionless geometry factor for shrinkage showed that the vertical or horizontal deformation was dominant, with the preponderant tendency of vertical deformation dependent on the increase in the moulding water content. Thus, in our opinion based on the observed shrinkage potential, in order to reduce the risk of shrinkage and the resulting cracking, the clay material for the sealing liner should be compacted at the left, 'dry' side of the Proctor curve (Fig. 2). Additionally, the supplementary measurements of saturated hydraulic conductivity following 1,2 , and 3 cycles of drying and wet- 
ting, which were performed to assess the sustainability of the clay sealing liner constructed from the tested clay materials, showed a significant increase in saturated hydraulic conductivity after drying and rewetting. Our observations are in full agreement with the data reported previously in literature (Akcanca and Aytekin, 2014; Albrecht and Benson, 2001; Baumgartl et al., 2004). None of the tested samples, regardless of the applied moulding water content, was able to maintain the saturated hydraulic conductivity presented directly after compaction. The observed value of $K_{s}$ increased by $4-5$ orders of magnitude and therefore reached the values typical for sandy soils. Thus, the practical operation of clay sealing layers as a part of a multilayer liner should be very careful and oriented towards retention, which allows sustenance of compacted clays saturated with water.

Our future studies should cover the selection of stabilizers allowing stabilization of the tested substrates as materials for liner construction, facilitating reduction of shrinkage, cracking, and increase the hydraulic conductivity after cyclic drying and wetting. Additionally, modelling studies allowing assessment of the retention and infiltration processes inside the landfill liner seem to be reasonable in order to assess the possibility of clay sealing saturation and assuring its long-term performance.

\section{CONCLUSIONS}

1. Both tested clay materials met the national and European legal and engineering criteria for acceptance for mineral liner construction.

2. Both tested clay materials showed in situ saturated conductivity lower than $1.0010^{-9} \mathrm{~m} \mathrm{~s}^{-1}$, which is a value required in Poland, European Union, and suggested by several guidelines. A significant decrease in hydraulic conductivity for a majority of the applied values of moulding water content was achieved, reaching a level of $10^{-11} \mathrm{~m} \mathrm{~s}^{-1}$. However, values in the range of $10^{-8}-10^{-9}$ were observed for both substrates and moulding water content of 0.13$0.15 \mathrm{~kg} \mathrm{~kg}^{-1}$. Thus, the applied moulding water content for liner construction should be carefully selected to ensure the required values of saturated hydraulic conductivity.

3 . The examined properties of both tested clay materials showed a relationship between the applied moulding water content and the swelling and shrinkage potential. Their shrinkage potential was assessed as moderate to very high. The shrinkage potential increased significantly for the moulding water contents higher than optimum for Proctor compaction.

4. In order to reduce the risk of shrinkage and resulting cracking, the clay material for a liner should be compacted at water content below the optimum for Proctor compaction, where the observed shrinkage potential is significantly lower.

5. Our measurements showed that the tested compacted clay materials were unable to maintain their low hydraulic conductivity after several cycles of drying and rewetting.
The observed increase in the hydraulic conductivity value in some cases of the cracked samples reached 4-5 orders of magnitude.

6. The practical operation of clay sealing layers as part of a multilayer liner should be very careful and oriented towards water retention, which allows sustenance of compacted clays saturated with water.

\section{REFERENCES}

Akcana F. and Aytekin M., 2014. Impact of wetting-drying cycles on the hydraulic conductivity of liners made of limestabilized sand-bentonite mixtures for sanitary landfills. Environ. Earth Sci., 72, 59-66.

Albrecht B. and Benson C., 2001. Effect of Desiccation on Compacted Natural Clays. J. Geotech. Geoenviron. Eng., 127(1), 67-75.

Aldaeef A.A. and Rayhani M.T., 2014. Hydraulic performance of Compacted Clay Liners (CCLs) under combined temperature and leachate exposures. Waste Management, 34, 2548-2560.

Arch J., 1998. Clay barriers in landfills. In: Environmental interactions of clays. Clays and environment. (Eds A. Parker, J.E. Rea). Springer, Berlin, Germany.

ASTM C566 - 13, 2013. Standard Test Method for Total Evaporable Moisture Content of Aggregate by Drying. ASTM International, West Conshohocken, PA, USA.

ASTM D5856 - 95, 2007. Standard Test Method for Measurement of Hydraulic Conductivity of Porous Material Using a RigidWall Compaction-Mold Permeameter. ASTM Int., West Conshohocken, PA, USA.

Bagchi A., 1990. Design, construction and monitoring of sanitary landfill. WileyPress, New York, USA.

Basma A.A., Al-Homoud A.S., Malkawi A.I.H., and Al-Bashabsheh M.A., 1996. Swelling-shrinkage behavior of natural expansive clays. Applied Clay Sci., 11(2-4), 211-227. DOI: 10.1016/S0169-1317(96)00009-9

Bauer B., Taubner H., and Tippkötter R., 2001. The measurement of mechanical and hydraulic consolidation of clayey substrates using an improved Proctor method (in German). Wasser und Boden, 53, 27-29.

Baumgartl T., Horn R., and Richards B.G., 2004. Soil Physical Processes in Capping Systems of Landfills - Possibilities of Capillary Break Capping. In: Waste Management (Eds A.L. Juhasz, G. Magesan, R. Naidu). Science Publishers Inc. Enfield, New Hampshire, USA.

Bello A.A., 2013. Hydraulic conductivity of three compacted reddish brown tropical soils. KSCE J. Civil Eng., 17(5), 939-948. DOI: 10.1007/s12205-013-0155-x.

Benson C.H. and Trast J.M., 1995. Hydraulic conductivity of thirteen compacted clays. Clays Clay Materials, 46(6), 669-681.

Bieganowski A., Chojecki T., Ryżak M., Sochan A., and Lamorski K., 2013. Methodological aspects of fractal dimension estimation on the basis of PSD. Vadose Zone J., 12, DOI: $10.2136 /$ vzj2012.0064.

Bronswijk J.J.B., 1990. Shrinkage geometry of a heavy clay soil at various stresses. Soil Sci. Soc. Am. J., 54, 1500-1502. 
Butt T.E., Lockley E., and Oduyemi K.O.K., 2008. Risk assessment of landfill disposal sites - State of the art. Waste Manag., 28, 952-964.

Council Directive 99/31/EC of 26 April 1999 on the landfill of waste.

Cuisinier O., Auriol J.C., and Le Borgne T., 2011. Microstructure and hydraulic conductivity of a compacted lime-treated soil. Eng Geol., 123(3),187-193, doi: 10.1016/j.enggeo. 2011.07.010.

Daniel D.E. and Koerner R.M., 1995. Waste Containment facilities. Guidance for Construction, Quality Assurance and Quality Control of Liner and Cover Systems. ASCE Press, New York, USA.

Daniel D.E. and Wu Y.K., 1993. Compacted clay liners and covers for air sities. J. Geotechnical Eng., ASCE, 119(2), 228-237.

Derkowski A., Franus W., Beran E., and Czimerova A., 2006. Properties and potential applications of zeolitic materials produced from fly ash using simple methods of synthesis. Powder Technol., 166/1, 47-54.

Gebhardt S., Fleige H., and Horn R., 2012. Anisotropic shrinkage of mineral and organic soils and its impact on soil hydraulic properties. Soil Till. Res., 125, 96-104. DOI: 10.1016/j.still.2012.06.017.

Grossman R.H., Brasher B.R., Franzmeier D.P., and Walker J.L., 1968. Linear extensibility as calculated from naturalclod bulk density measurements. Soil Sci. Soc. Am. Proc., 32, 570-573.

Hamdi N. and Srasra E., 2013. Hydraulic conductivity study of compacted clay soils used as landfill liners for an acidic waste. Waste Manag., 33(1), 60-6. DOI: 10.1016/j. wasman.2012.08.012

Horn R., Fleige H., and Zimmermann I., 2015. Anthropogenic Structure Changes in Soils (in German). Handbuch der Bodenkunde. Chapter 6.2. Wiley Publ. (in press)

Horn R. and Stępniewski W., 2004. Modification of mineral liner to improve its long-term stability. Int. Agrophysics, $18,317-323$.

Journal of Laws item 523, 2013. Regulation of the Minister of Environment of 30 April 2013 about landfilling of wastes (in Polish). Sejm of the Republic of Poland, Warsaw, Poland.

Laner D., Crest M., Schraff H., Morris J.W.F., and Barlaz M.A., 2012. A review of approaches for the long-term management of municipal solid waste landfills. Waste Manag., 32, 498-512.

Laner D., Fellner J., and Brunner P. H., 2011. Future landfill emissions and the effect of final cover installation - A case study. Waste Manag., 31, 1522-1531.

Lou W.F. and Nair J., 2009. The impact of landfilling and composting on greenhouse gas emission -A review. Bioresource Technol., 100, 3792-3798.
Osinubi K.J. and Nwaiwu Ch.M.J., 2005. Hydraulic conductivity of compacted lateritic soil. Geotech Geoenviron Eng., 131(8),1034-1041, doi: 10.1061/(ASCE)1090-0241(2005) 131:8(1034)

Pires L.F., Bacchi O.O.S., and Reichardt K., 2005. Gamma ray computed tomography to evaluate wetting/drying soil structure changes. Nuclear Instruments and Methods in Physics Research, B 42, 857-863.

PKN-CEN ISO/TS 17892-12, 2009. Geotechnical investigation and testing. Laboratory testing of soil. Part 12: Determination of Atterberg limits (in Polish). Polish Committee for Standardization, Warsaw, Poland.

PKN-CEN ISO/TS 17892-5, 2009. Geotechnical investigation and testing. Laboratory testing of soil. Part 5: Incremental loading oedometer test (in Polish). Polish Committee for Standardization, Warsaw, Poland.

PKN-CEN ISO/TS 19892-10, 2009. Geotechnical investigation and testing. Laboratory testing of soil. Part 10: Direct shear tests (in Polish). Polish Committee for Standardization, Warsaw, Poland.

PN-B-04481: 1988. Soils. Researches of soil samples (in Polish). Polish Committee for Standardization, Warsaw, Poland.

Rowe R.K., Quigley R.M., and Booker J.R., 1995. Clayey barrier systems for waste disposal facilities. E and FN SPON, London, UK.

Ryżak M. and Bieganowski A., 2010. Determination of particle size distribution of soil using laser diffraction - comparison with areometric method. Int. Agrophys., 24, 177-181.

Seguel O. and Horn R., 2006. Structure properties and pore dynamics in aggregate beds due to wetting and drying cycles. J. Plant Nutrition Soil Sci., 169, 221-232.

Simon F.G. and Müller W.W., 2004. Standard and alternative landfill capping design in Germany. Environmental Sci. Policy, 7, 277-290.

Tripathy S. and Rao K.S.S., 2009. Cyclic swell-shrink behavior of a compacted expansive soil. Geotech. Geol. Eng., 27, 89-103, DOI 10.1007/s10706-008-9214-3

Widomski M.K., Beck Broichsitter S., Zink A., Fleige H., Horn R., and Stępniewski W., 2015. Numerical modeling of water balance for temporary landfill cover in North Germany. J. Plant Nutrition Soil Sci., 178, 401-412, DOI: 10.1002/ jpln.201400045.

Whalley W.R., Matthews G.P., and Ferraris S., 2012. The effect of compaction and shear deformation of saturated soil on hydraulic conductivity. Soil Till. Res., 125, 421-428.

Wysokiński L., 2007. Principles of assessing the suitability of cohesive soils of Poland for the construction of mineral insulating barriers (in Polish). ITB, Ministry of Environment, Warsaw, Poland.

Zhang S.L., Grip H., and Lovdahl L., 2006. Effect of soil compaction on hydraulic properties of two loess soils in China, Soil Till. Res., 90, 117-125, DOI:10.1016/j.still.2005.08.012 